\title{
Tandem Carotid Lesions in Acute Ischemic Stroke: Mechanisms, Therapeutic Challenges, and Future Directions
}

\section{ABSTRACT}

SUMMARY: Approximately $15 \%$ of patients undergoing endovascular thrombectomy for anterior circulation acute ischemic stroke have a tandem lesion, defined as a severe stenosis or occlusion of the cervical internal carotid artery ipsilateral to its intracranial occlusion. Patients with tandem lesions have worse outcomes than patients with isolated intracranial occlusions, but the optimal management of their carotid lesions during endovascular thrombectomy remains controversial. The main options commonly used in current practice include acute stent placement in the carotid lesion versus thrombectomy alone without definitive revascularization of the carotid artery. While treatment decisions for these patients are often complex and strategies vary according to clinical, anatomic, and technical considerations, only results from randomized trials comparing these approaches are likely to strengthen current recommendations and optimize patient care.

A pproximately $15 \%$ of patients undergoing endovascular thrombectomy (EVT) for anterior circulation acute ischemic stroke (AIS) have a tandem lesion (TL), defined as a severe stenosis or occlusion of the cervical internal carotid artery (c-ICA) ipsilateral to its intracranial occlusion. ${ }^{1}$ Studies of patients with TLs have generally included more men than women (approximately 60\% versus $40 \%){ }^{2}$ which likely reflects a true difference in the prevalence of carotid atherosclerosis according to sex. ${ }^{3}$ Epidemiologic studies have also shown that extracranial artery disease is more prevalent among whites than blacks and Asians. ${ }^{3}$

Patients with TLs have worse outcomes than patients with isolated intracranial occlusions, with high rates of disability and death. ${ }^{4}$ Intravenous thrombolysis (IVT) is less effective in patients with TLs, presumably owing to a larger clot burden and low

Received February 23, 2020; accepted after revision March 17.

From the Departments of Medicine (Neurology) (A.Y.P., G.J., C.S.), and Radiology (Neuroradiology) (D.R.), Centre Hospitalier de l'Université de Montréal, Montréal, Québec, Canada; Neurovascular Group (A.Y.P., G.J., C.S.), Axe Neurosciences, Centre de Recherche du Centre Hospitalier de l'Université de Montréal, Montréal, Québec, Canada; Stroke Center (L.D.), Department of Neurology, Neurological Hospital, Hospices Civils de Lyon, Lyon, France; and EA 7425 HESPER (L.D.), Health Services and Performance Research, Claude Bernard Lyon 1 University, Lyon, France.

AQ:corrs Please address correspondence to Alexandre Y. Poppe, MD, Department of Medicine (Neurology), Centre Hospitalier de l'Université de Montréal, 900 rue St-Denis, R04-758, Montréal, Québec, Canada; e-mail: alexandre.poppe.chum@ssss.gouv.qc.ca

- Indicates open access to non-subscribers at www.ajnr.org http://dx.doi.org/10.3174/ajnr.A6582 anterograde flow impeding thrombolytic drug access to the intracranial thrombus. ${ }^{4}$

Relatively few patients with TLs were included in the major randomized controlled trials of EVT, and management of the cICA was generally not specified by protocol or analyzed post hoc. In the absence of robust randomized trial data, no firm recommendations about optimal management can be forwarded, as reflected in the most recent American ${ }^{5}$ and European ${ }^{6}$ guidelines.

For this population of patients with AIS undergoing EVT, treatment decisions are often complex, and strategies vary according to clinical, anatomic, and technical considerations in addition to physician preference.

This article aims to review the pathophysiologic substrate of AIS related to TLs, the management options available for patients with such lesions, and directions for future research.

\section{Mechanism of Stroke and Etiology of the Cervical Carotid Lesion}

In paints with TLs, the mechanism of stroke usually involves artery-to-artery embolization of the clot from an atherosclerotic plaque or from a site of arterial dissection in the ICA to the intracranial circulation.

Atherosclerotic Plaque versus Dissection. Tandem lesions are most often atherosclerotic in nature, with an underlying plaque becoming unstable, rupturing, and triggering local thrombus 
formation with distal embolization of thrombus fragments. Published series of acute TLs suggest that about $60 \%-70 \%$ are due to atherosclerotic plaque; $20 \%-30 \%$, due to dissection; and the remainder, attributable to carotid webs and cardiac emboli. ${ }^{2,7}$ In this last group, a large cardiac embolus presumably lodges in the c-ICA (possibly due to underlying atherosclerotic stenosis) and fragments to embolize in the intracranial circulation.

Radiologic differentiation of these various etiologies of carotid stenosis is possible and does not necessarily require conventional angiography. Noninvasive modalities like MRA and CTA have been found to identify carotid dissection with similar sensitivity and specificity. ${ }^{8}$ In most settings, acute stroke imaging involves CTA. With this technique, dissection is suggested by the presence of a tapered or flame-shaped stenosis or occlusion occurring $\geq 2 \mathrm{~cm}$ from the ICA origin, often near the skull base. ${ }^{9}$ Classic findings such as a double lumen or intimal flap may be found, but less commonly. ${ }^{10}$ On plain CT, axial sections at the skull base can sometimes identify an ICA wall hematoma, appearing as a hyperdense or tissue-density crescent. In contrast, c-ICA occlusions of atherosclerotic etiology are generally at or near the ICA origin and may be associated with adjacent calcified plaque. Atherosclerosis in other cervical arteries may also favor this diagnosis over dissection.

Patients with TLs due to carotid dissection tend to have more favorable demographic profiles, being younger with fewer comorbidities than patients with atherosclerotic lesions. ${ }^{7}$ Acute stent placement for an ICA dissection is less commonly performed than for atherosclerotic lesions, ${ }^{7,11,12}$ most likely due to anatomic considerations (dissected segments may be long and tortuous) and the generally more favorable natural history of dissection, which involves spontaneous vessel wall healing with recanalization in up to $70 \%$ of patients. ${ }^{13}$ If stent placement is performed for carotid dissection, the true lumen must be identified and multiple stents may be required to reconstruct the artery, though dissected flaps may be more easily opened by stent placement then hardened atherosclerotic plaques. Addressing the intracranial occlusion first and avoiding routine c-ICA stent placement in patients with dissection appears to be a safe approach. ${ }^{12}$ Conversely, atherosclerotic lesions represent an important tech-

AQ: B nical challenge, highlighted by longer procedural times, lower recanalization rates, and more procedural complications in some series. ${ }^{14}$ If stent placement is performed for carotid lesions due to atherosclerotic plaque, angioplasty before and sometimes after stent placement may be required, particularly in calcified plaques.

Patients with dissection may thus be distinguished from those with atherosclerotic plaque as having different pathologies with potentially different treatment approaches and prognoses. ${ }^{15}$

Severity of the Carotid Stenosis. The severity of the cervical carotid lesion, that is, whether it is completely occlusive or merely stenotic, may also influence both the technical approach and outcomes. Traversing a complete occlusion may be more challenging and must often be done "blindly" because the distal lumen cannot be opacified. However, outcomes appear similar regardless of whether cervical ICA pathology is occlusive or stenotic. ${ }^{16}$

A distinct subgroup comprises patients with isolated acute cICA occlusion presenting with symptoms of ipsilateral hemispheric

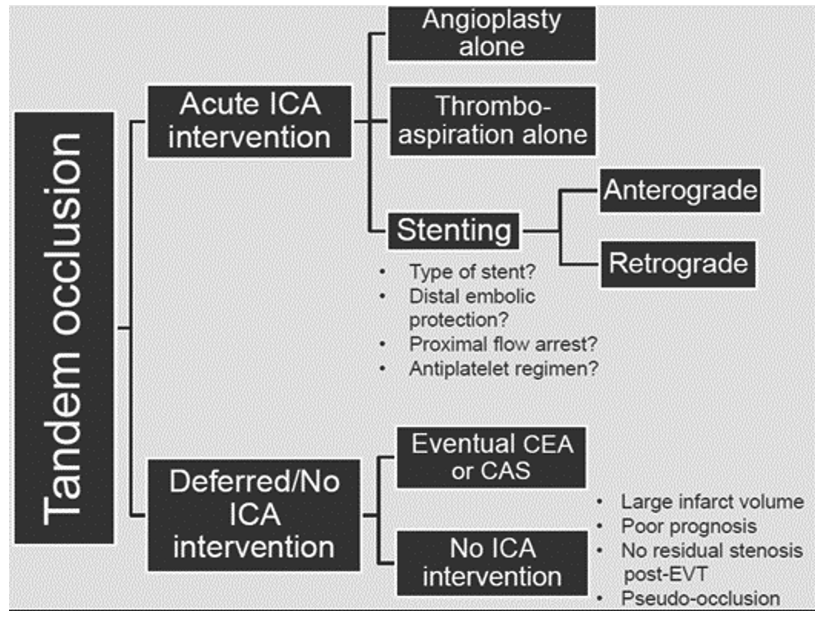

FIG 1. Schematic summarizing the main approaches to managing cervical carotid lesions in patients with tandem occlusions undergoing thrombectomy for acute stroke. CEA indicates carotid endarterectomy; CAS, carotid artery stent placement.

ischemia, usually due to impaired carotid artery territory perfusion (acute hemodynamic stroke) rather than intracranial clot embolization. These patients are infrequent in the setting of AIS, generally have a more favorable prognosis than patients with TLs, and are less often considered for EVT, given the absence of an intracranial occlusion. $^{14}$

Radiologic Differentiation of True Carotid Occlusion from Pseudo-Occlusion. It is sometimes difficult to reliably identify patients with true TLs on CTA because about one-third of patients with presumed c-ICA tandem occlusions using this technique actually have intracranial carotid terminus occlusions (socalled ICA pseudo-occlusions) with delayed opacification of the c-ICA due to slow anterograde flow and a stagnant column of nonopacified blood. ${ }^{17,18}$ In such cases, the pseudo-occlusion is usually only confirmed on angiography; however, delayed-phase CTA of the neck may be helpful in confirming true c-ICA occlusions. ${ }^{19}$ Identifying a true tandem occlusion before EVT is helpful to properly plan the angiographic procedure, including determining how to traverse the c-ICA occlusion and permitting sufficient forethought regarding the need for c-ICA stent placement or angioplasty.

\section{Treatment Strategies and Challenges}

The optimal management of patients with AIS and TLs undergoing EVT remains uncertain, being subject to multiple clinical, anatomic, and technical considerations.

Should Acute Carotid Stent Placement Be Performed in Conjunction with Thrombectomy? Two main approaches exist in patients with AIS with TLs undergoing EVT (Fig 1). The first is to traverse the c-ICA lesion, perform intracranial clot retrieval, and leave the c-ICA largely untreated for possible endarterectomy or stent placement in the ensuing days or weeks. This approach includes less definitive c-ICA recanalization strategies such as balloon angioplasty alone or thrombo-aspiration via a large-bore catheter and is sometimes used as an initial approach, with 
Postulated advantages of each treatment approach for patients with tandem lesions (acute stent placement versus no acute stent placement)

Potential Advantages of Acute Stent Placement

Potential Advantages of No Acute Stent Placement

Treatment of the causative embolic lesion and lower risk of stroke recurrence

Improvement of cerebral perfusion with potential attenuation of infarct progression

Contribution to spontaneous intracranial clot lysis

Lower risk of intracranial hemorrhage (avoidance of hyperperfusion, acute antiplatelet agents)

Lower risk of iatrogenic artery-to-artery embolization during stent deployment

No risk of in-stent thrombosis

Avoids delays in intracranial recanalization (if stent placement before thrombectomy)

Lower risk of procedural bradycardia and hypotension from carotid baroreceptor activation with stent deployment

intraprocedural, stepwise progression to stent placement only if dynamic re-occlusion of the c-ICA occurs despite angioplasty. The second, more definitive approach is to recanalize the c-ICA using stent placement systematically during EVT, either before or following intracranial thrombectomy. These treatment strategies exemplify the competing risks that must be balanced in patients with TLs-that is, ischemic stroke progression or recurrence on the one hand versus intracranial hemorrhage on the other. Both are widely used in clinical practice, as seen in the STRATIS EVT registry (https://www.medtronic.com/content/ $\mathrm{dam} / \mathrm{medtronic-com/products/neurological/revascularization-}$

AQ: C stroke/stratis-systems-of-care.pdf) in which $54 \%$ of patients with TLs were acutely stented and $46 \%$ were not. ${ }^{1}$

The putative advantages of acute stent placement in the c-ICA

$\mathrm{T} 1$ and foregoing acute stent placement are summarized in the Table. Acute c-ICA stent placement may more effectively treat the cause of stroke, favor intracranial clot lysis, and decrease the risk of recurrence while improving overall cerebral perfusion. ${ }^{20}$ Acute stent placement is also associated with greater early c-ICA patency and perhaps better early neurologic improvement than angioplasty alone. ${ }^{21}$ However, foregoing acute stent placement may avoid early administration of antiplatelet agents, which may increase the risk of intracranial hemorrhage in the immediate postrecanalization phase, particularly in patients having received IVT or having a large core of cerebral infarction. ${ }^{22,23}$ Definitive c-ICA revascularization can also then be performed with an operation or stent placement in a delayed, more secure setting. Furthermore, acute stent placement carries an inherent risk of in-stent thrombosis, which may confer a worse prognosis. ${ }^{24}$

Should the Intracranial or Extracranial Lesions Be Treated First? Stent placement may be performed either before intracranial thrombectomy ("anterograde") or after thrombectomy ("retrograde"). Published series have shown that both approaches are commonly used ${ }^{25}$ and suggest that both yield similar functional outcomes despite differences in recanalization times. ${ }^{26,27}$

There are theoretic advantages to the retrograde technique, including shorter intracranial recanalization time and avoidance of potential snagging of the retrievable stent in the struts of an already-deployed c-ICA stent. ${ }^{28}$ Moreover, re-establishing anterograde carotid flow may provoke distal migration of the intracranial thrombus, making it less amenable to thrombectomy. Stent placement of the c-ICA earlier in the procedure also subjects the patient to potential hemodynamic instability due to baroreceptor activation while cerebral perfusion is still impaired by the presence of an intracranial occlusion. Furthermore, in some cases, merely traversing the ICA lesion with catheters to access the intracranial thrombus is sufficient to dilate the stenosis or occlusion and potentially obviate the need for stent placement. A potential disadvantage of the retrograde approach is that treating the extracranial carotid lesion after intracranial recanalization may be associated with recurrent embolization during stent deployment. Furthermore, in some cases, specific technical circumstances may mandate an anterograde approach to gain access to the intracranial circulation. The debate regarding the order of stent placement relative to thrombectomy has recently been circumvented by some authors who have developed techniques using nearly simultaneous c-ICA revascularization and intracranial stent-retriever thrombectomy; however, adoption of this approach remains limited thus far. ${ }^{29,30}$

What Type of Stent Should Be Used? Dual-layer stents contain a second micromesh layer to theoretically better cover the atherosclerotic plaque and more effectively prevent dislodgement of debris. ${ }^{31}$ However, some studies suggest that dual-layer stents may be associated with a higher rate of acute in-stent thrombosis when used for a TL during EVT, ${ }^{31,32}$ while others do not. ${ }^{33}$ Nevertheless, their use in the acute setting is not widespread. Otherwise, there are few data favoring one stent type over another in the acute setting (eg, open- or closed-cell). Balloon angioplasty before or following stent deployment may be performed to ensure an optimal intraluminal diameter, but the radial force of the stent may often be sufficient to achieve a satisfactory angiographic result.

What Antithrombotic Regimen is Preferred? If ICA stent placement is performed, antithrombotic medication must generally be given to prevent acute in-stent thrombosis and its associated potential risks of distal embolization or stent occlusion. However, the choice of optimal antithrombotic therapy in the setting of acute ICA stent placement during EVT remains unknown. The risk of in-stent thrombosis must be balanced against the risk of hemorrhagic transformation of infarcted cerebral tissue, with this latter risk of particular concern in patients having $\mathrm{IVT}^{34}$ or having a large core of infarction. It is known that early administration of $300 \mathrm{mg}$ of IV aspirin after IVT is associated with excess intracerebral hemorrhage and no clinical benefit, at least among patients not treated with EVT. ${ }^{34}$ Therefore, whether IVT was given should influence the choice of acute antithrombotic medications.

The risk of intracranial hemorrhage in stented patients varies widely between series, with some ${ }^{22,35}$ suggesting much higher

\section{.}


rates than those seen in the major EVT trials and other larger series suggesting no excess risk of bleeding, ${ }^{1,2}$ even among patients treated with IVT. ${ }^{23,36}$ Furthermore, the use of IVT appears safe and likely beneficial in patients with TLs who undergo stent placement. ${ }^{37}$ In the Thrombectomy in Tandem Occlusion (TITAN) cohort, $24.7 \%$ of patients developed hemorrhagic infarction, and $14.2 \%$, a parenchymal hematoma, similar to rates seen after thrombectomy for isolated intracranial occlusions. ${ }^{23}$ In this cohort, acute carotid stent placement and antiplatelet therapy use were not predictors of parenchymal hematoma or hemorrhagic infarction.

Different antithrombotic regimens are described in the acute phase after acute ICA stent placement, including administration of aspirin alone $e^{38}$ or in combination with clopidogrel at various dosages as well as the administration of glycoprotein IIb/IIIa inhibitors and heparin. Series in which glycoprotein IIb/IIIa inhibitors were given either intravenously or intra-arterially poststenting seem to demonstrate an excess risk of intracranial hemorrhage, suggesting that enteral antiplatelet agents may be safer in this setting. ${ }^{22}$

A small series evaluating delayed stent patency found greater rates of in-stent thrombosis among patients treated with aspirin only as opposed to aspirin and clopidogrel. ${ }^{24}$ Stent thrombosis in this series was also attributed to the routine use of long, closedcell stents. ${ }^{24}$ In a retrospective series of 98 patients with stroke with an atherosclerotic TL who underwent acute stent placement and were given antiplatelet monotherapy with $250 \mathrm{mg}$ of aspirin in the acute phase, the rate of stent occlusion within 7 days after stent placement was $10.3 \%{ }^{38}$ In this series, early stent occlusion had no clinical consequences in terms of recurrence of stroke or worse outcome. This finding might be related to the longstanding nature of the atherosclerotic ICA stenosis, which may improve collateralization and hemodynamic tolerance.

Although practice varies widely, a reasonable strategy would be administration of a periprocedural aspirin bolus (about $300 \mathrm{mg}$ ), either orally, rectally, or intravenously (where available) with a clopidogrel bolus (300 mg) given orally. In patients at higher risk of bleeding, particularly those having received IV thrombolysis or having a large infarct core, the clopidogrel bolus may be delayed until after repeat brain imaging within the first 12-24 hours.

Even in cases of nonacute ICA stent placement, antiplatelet regimens are not uniform, though most experts suggest that the duration of dual-antiplatelet therapy beyond the acute phase should be at least $4-6$ weeks, as extrapolated from the Carotid Revascularization Endarterectomy versus Stenting Trial (CREST) protocol, followed by a long-term single-antiplatelet agent (usually aspirin). ${ }^{39}$ Unlike acute stent placement, in this more elective setting, patients can be administered antiplatelet agents before stent placement, which may theoretically decrease the risk of stent thrombosis.

Only limited data exist regarding the use of ticagrelor or prasugrel in carotid stent placement, and their use in this setting cannot be routinely recommended. ${ }^{40}$ Cangrelor, an intravenous antiplatelet agent characterized by rapid onset and offset of action, has been used in some centers, but data are currently insufficient to recommend its routine use. ${ }^{41}$

Some interventionalists administer IV heparin when stent placement occurs during EVT, ${ }^{42}$ theoretically decreasing the risk of stent thrombosis while awaiting the onset of action of antiplatelet agents. Higher doses of heparin $(70 \mathrm{U} / \mathrm{kg})$ are associated with higher rates of intracerebral hemorrhage, particularly in combination with dual-antiplatelet regimens. ${ }^{43}$ With lower doses of approximately $30 \mathrm{U} / \mathrm{kg}$, hemorrhagic complications do not appear to be more common, though clinical outcomes are similarly not better. Strong recommendations can, therefore, be made regarding the use of lower-dose IV heparin in these patients. ${ }^{44}$

Further data to help guide the use of aspirin and heparin among patients undergoing EVT should be provided by the ongoing Multicenter Randomized CLinical trial of Endovascular treatment for Acute ischemic stroke in the Netherlands; the effect of periprocedural MEDication: antiplatelet agents, heparin, both or neither (MR CLEAN-MED) randomized trial (ISCRTN76741621).

Is There a Role for Embolic Protection Devices? For embolic protection devices using either distal filters or proximal flow reversal, data pertain almost exclusively to patients undergoing nonacute carotid stent placement for primary or secondary stroke prevention. The benefit of embolic protection devices during stent placement remains debated, and in the absence of high-quality comparative studies, their use is not universally endorsed. ${ }^{45}$ Given the urgency of EVT for stroke and potential patient instability, embolic protection devices are rarely used in this setting. ${ }^{11}$

Delayed Carotid Revascularization in Nonstented Patients. Among patients not undergoing acute stent placement, it is reasonable to consider delayed revascularization, either with carotid endarterectomy or stent placement, in a secondary prevention paradigm. Although few data exist on the proportion of patients with TLs undergoing EVT who later benefit from deferred ICA revascularization, this number is likely relatively small (only 4 of 13 patients in the Endovascular Treatment for Small Core and Anterior Circulation Proximal Occlusion With Emphasis on Minimizing CT to Recanalization Times [ESCAPE] trial). ${ }^{46}$ This small number may be due to poor poststroke recovery, large stroke volume, hemorrhagic transformation, or sufficient c-ICA revascularization by the bougie effect of cross-lesional catheter advancement. Clearly, patients with TLs undergoing EVT for stroke are a more severely affected population than most patients included in studies of nonacute carotid revascularization whose index events were generally minor strokes and retinal ischemic events. ${ }^{47}$

Consideration of delayed carotid intervention also raises the issue of how and when follow-up carotid imaging should be performed in these patients, both for those who are stented acutely (to assess delayed stent patency) and those who are not (to assess indications for delayed revascularization). Noninvasive imaging by carotid Doppler sonography or by CTA can reasonably be performed within a few days to weeks of the index stroke, with timing adapted to the patient's clinical status.

Other Management Approaches. Other treatment options are used only anecdotally, and little literature supports their use. One includes "sacrifice" of the c-ICA by coil embolization, so as to address the source of arterial emboli, and is more often used in situations in which c-ICA intraluminal thrombus suggests a high risk of embolization and adequate collateral flow is provided via the circle of Willis. ${ }^{34}$ Similarly, in some patients who have 


\begin{tabular}{|c|c|c|}
\hline & Favours no stenting & Favours stenting \\
\hline ICA lesion etiology & Dissection & Atherosclerosis \\
\hline Infarct core volume & Large infarct/low ASPECTS & Small infarct/high ASPECTS \\
\hline $\begin{array}{l}\text { Quality of final intracranial } \\
\text { recanalization }\end{array}$ & None or poor (mTICI 0-1) & $\begin{array}{l}\text { Complete or near-complete } \\
\text { (mTICI 2b-3) }\end{array}$ \\
\hline $\begin{array}{l}\text { Collateral circulation via } \\
\text { circle of Willis }\end{array}$ & $\begin{array}{l}\text { Good collaterals/complete } \\
\text { circle of Willis } \\
\end{array}$ & $\begin{array}{l}\text { Poor collaterals/incomplete } \\
\text { circle of Willis }\end{array}$ \\
\hline \begin{tabular}{|l|} 
Dynamic ICA re-occlusion on \\
angiography \\
\end{tabular} & No active re-occlusion & Active re-occlusion \\
\hline Use of IV thrombolysis & Yes & No \\
\hline Systemic bleeding risk & Higher risk & Lower risk \\
\hline $\begin{array}{l}\text { Indication for long-term } \\
\text { anticoagulation } \\
\end{array}$ & Present & Absent \\
\hline
\end{tabular}

FIG 2. Clinical and radiologic factors influencing the decision to favor acute stent placement or no stent placement for patients with tandem lesions undergoing thrombectomy. placement be performed ${ }^{55,56}$ while the Endovascular Therapy Following Imaging Evaluation for Ischemic Stroke (DEFUSE-3) trial did not detail treatment approaches or outcomes in the TL subgroup. ${ }^{57,58}$ Optimal acute management of the cervical ICA lesion in patients with TLs undergoing EVT, therefore, remains unclear.

Evidence from Observational Studies. Our international survey of stroke experts further highlighted this therapeutic uncertainty, with $75 \%$ of respondents admitting to having equipoise regarding therapy for these patients. ${ }^{11}$ The existence of community equipoise is also echoed in several studies that were all observational and often only described stented patients. Four main meta-analyses of these persistent c-ICA occlusion but favorable intracranial recanalization with adequate cross-filling, the c-ICA occlusion may simply be left untouched. Another approach that remains marginally used is emergent carotid endarterectomy in the hours following thrombectomy. ${ }^{48}$ In cases of chronic c-ICA occlusions with recurrent embolic or hemodynamic ischemia, randomized trials have demonstrated that extracranial-to-intracranial arterial bypass procedures are not useful, so this delayed approach is not recommended. ${ }^{49,50}$

\section{Current Evidence for Management}

Data from the Major EVT Trials. High-quality evidence for treatment of patients with TLs undergoing EVT remains limited. Three of the major randomized EVT trials excluded patients with a TL. ${ }^{51-53}$ In the remaining trials, these patients represented $13 \%-$ $32 \%$ of the study population.

The treatment effect of thrombectomy in patients with TLs was comparable with that of patients with isolated intracranial AQ: F occlusions in the Highly Effective Reperfusion using Multiple Endovascular devices (HERMES) collaboration. However, this patient-level meta-analysis included only 122 patients with TLs, ${ }^{54}$ and while a clear superiority of EVT over standard care was demonstrated, little has been published about how the c-ICA was addressed in the individual trials. ${ }^{46}$

Acute stent placement was used in a minority of patients with TLs in the ESCAPE (26.7\%), the Multicenter Randomized Clinical Trial of Endovascular Treatment for Acute Ischemic Stroke in the Netherlands (MR CLEAN), (40\%), and Endovascular Revascularization With Solitaire Device Versus Best Medical Therapy in Anterior Circulation Stroke Within 8 Hours (REVASCAT) (47.4\%) trials. ${ }^{5}$ Late-window EVT trials have similarly not provided meaningful guidance for patients with TLs. The DWI or CTP Assessment with Clinical Mismatch in the Triage of Wake-Up and Late Presenting Strokes Undergoing Neurointervention with Trevo (DAWN) trial included 27 patients with TLs in the EVT arm but mandated that no c-ICA stent smaller case series have been published, ${ }^{20,25,26,59}$ most with relatively few patients not having undergone acute stent placement and only $1^{59}$ focusing primarily on whether acute stent placement was associated with different clinical outcomes than no stent placement. The large multicenter retrospective cases-series of 482 patients from the TITAN group was not included in these metaanalyses but suggests that stented patients receiving acute antiplatelet medications have more favorable outcomes than patients treated with angioplasty alone or those with no acute ICA intervention. ${ }^{37}$ Another large multicenter EVT registry ${ }^{1}$ also found better outcomes among stented patients, with both nonrandomized series suggesting $15 \%-20 \%$ higher rates of favorable outcome (mRS 0-2) at 90 days. Clearly, even adjusted analyses of observational data cannot entirely control for indication biases that may have favored stent placement in patients with an a priori better prognosis.

The Endovascular Acute Stroke Intervention (EASI) trial demonstrated that randomization of patients with TLs is possible. ${ }^{60} \mathrm{In}$ this single-center pragmatic care trial performed before the MR CLEAN results, patients with stroke were randomized to best medical management alone versus best medical management with EVT, and patients allocated to EVT who had a TL identified on CTA or conventional angiography underwent a second randomization, allocating them to acute ICA stent placement or not. The 24 patients included had similar functional outcomes whether stented or not but were too few to generate practice-changing conclusions. Nonetheless, the data have served as a proof-of-concept for the forthcoming Endovascular Acute Stroke InterventionTandem Occlusion (EASI-TOC) trial (NCT04261478). ${ }^{61}$

In the absence of high-level data to guide management decisions and if randomization in a clinical trial is not possible, observational data do suggest that some clinical and radiologic factors may favor acute stent placement, while others may argue against it (Fig 2).

\section{Conclusions and Future Directions}

Strokes caused by a TL represent up to one-fifth of all strokes treated with EVT. Although randomized trials were not designed 
to evaluate the efficacy of EVT in these patients, a subgroup analysis of individual TL patient data suggests that EVT results in better neurologic outcomes than standard treatment using IVT alone. Observational data suggest that combining acute c-ICA stent placement with intracranial thrombectomy may be the best strategy to treat patients with TLs, being associated with better functional outcomes and carotid patency. However, because robust scientific evidence is still lacking and antiplatelet agents and endovascular techniques and tools are in constant evolution, no consensus remains regarding the ideal therapeutic strategy for these patients. In this context, only the results of randomizedcontrolled trials like TITAN (NCT03978988) and EASI-TOC ${ }^{62}$ will help determine the benefit of acute stent placement, or absence thereof, in patients with TLs.

AQ:disc

Disclosures: Alexandre Y. Poppe-RELATED: Grant: Canadian Stroke Trials for Optimized Results, Comments: networking seed grant for Randomized Trial of Tandem Carotid Lesions (EASI-TOC)*; UNRELATED: Other: Servier Laboratories, Bristol-Myers Squibb-Pfizer, Bayer AG, Comments: Servier Laboratories, institutional support for stroke fellowship; Bristol-Myers Squibb-Pfizer, Bayer AG, institutional support for electronic medical record service; OTHER RELATIONSHIPS: I am the Principal Investigator for a randomized trial studying patients with tandem carotid lesions undergoing endovascular thrombectomy (EASI-TOC, NCT04261478). Daniel Roy-UNRELATED: Payment for Development of Educational Presentations: Radiological Society of Quebec, Comments: payments for production of a workshop on CT angiography. *Money paid to the institution.

\section{REFERENCES}

1. Jadhav AP, Zaidat OO, Liebeskind DS, et al. Emergent management of tandem lesions in acute ischemic stroke. Stroke 2019;50:428-33 CrossRef Medline

2. Papanagiotou P, Haussen DC, Turjman F, et al; TITAN Investigators. Carotid stenting with antithrombotic agents and intracranial thrombectomy leads to the highest recanalization rate in patients with acute stroke with tandem lesions. JACC Cardiovasc Interv 2018;11:1290-99 CrossRef Medline

3. Rockman CB, Hoang H, Guo Y, et al. The prevalence of carotid artery stenosis varies significantly by race. J Vasc Surg 2013;57:327-37 CrossRef Medline

4. Kim YS, Garami Z, Mikulik R, et al. Early recanalization rates and clinical outcomes in patients with tandem internal carotid artery/ middle cerebral artery occlusion and isolated middle cerebral artery occlusion. Stroke 2005;36:869-71 CrossRef Medline

5. Powers WJ, Rabinstein AA, Ackerson T, et al. Guidelines for the Early Management of Patients with Acute Ischemic Stroke: 2019 Update to the 2018 Guidelines for the Early Management of Acute Ischemic Stroke-A Guideline for Healthcare Professionals From the American Heart Association/American Stroke Association. Stroke 2019;50:e344-418 CrossRef Medline

6. Turc G, Bhogal P, Fischer U, et al. European Stroke Organisation (ESO)-European Society for Minimally Invasive Neurological Therapy (ESMINT) Guidelines on Mechanical Thrombectomy in Acute Ischaemic Stroke Endorsed by Stroke Alliance for Europe (SAFE). Eur Stroke J 2019;4:6-12 CrossRef Medline

7. Gory B, Piotin M, Haussen DC, et al; TITAN Investigators. Thrombectomy in acute stroke with tandem occlusions from dissection versus atherosclerotic cause. Stroke 2017;48:3145-48 CrossRef Medline

8. Provenzale JM, Sarikaya B. Comparison of test performance characteristics of MRI, MR angiography, and CT angiography in the diagnosis of carotid and vertebral artery dissection: a review of the medical literature. AJR Am J Roentgenol 2009;193:1167-74 CrossRef Medline

9. Downer J, Nadarajah M, Briggs E, et al. The location of origin of spontaneous extracranial internal carotid artery dissection is adjacent to the skull base. J Med Imaging Radiat Oncol 2014;58:40814 CrossRef Medline

10. Lee VH, Brown RD Jr, Mandrekar JN, et al. Incidence and outcome of cervical artery dissection: a population-based study. Neurology 2006;67:1809-12 CrossRef Medline

11. Jacquin G, Poppe AY, Labrie M, et al. Lack of consensus among stroke experts on the optimal management of patients with acute tandem occlusion. Stroke 2019;50:1254-56 CrossRef Medline

12. Marnat G, Buhlmann M, Eker OF, et al. Multicentric experience in distal-to-proximal revascularization of tandem occlusion stroke related to internal carotid artery dissection. AJNR Am J Neuroradiol 2018;39:1093-99 CrossRef Medline

13. Baracchini C, Tonello S, Meneghetti G, et al. Neurosonographic monitoring of 105 spontaneous cervical artery dissections: a prospective study. Neurology 2010;75:1864-70 CrossRef Medline

14. Gliem M, Lee JI, Barckhan A, et al. Outcome and treatment effects in stroke associated with acute cervical ICA occlusion. PLoS One 2017;12:e0170247 CrossRef Medline

15. Eker OF, Panni P, Dargazanli C, et al. Anterior circulation acute ischemic stroke associated with atherosclerotic lesions of the cervical ICA: a nosologic entity apart. AJNR Am J Neuroradiol 2017;38:213845 CrossRef Medline

16. Anadani M, Spiotta A, Alawieh A, et al; TITAN (Thrombectomy In TANdem Lesions) Investigators. Effect of extracranial lesion severity on outcome of endovascular thrombectomy in patients with anterior circulation tandem occlusion: analysis of the TITAN registry. J Neurointerv Surg 2019;11:970-74 CrossRef Medline

17. Grossberg JA, Haussen DC, Cardoso FB, et al. Cervical carotid pseudo-occlusions and false dissections: intracranial occlusions masquerading as extracranial occlusions. Stroke 2017;48:774-77 CrossRef Medline

18. Kappelhof M, Marquering HA, Berkhemer OA, et al; MR CLEAN Investigators. Accuracy of CT angiography for differentiating pseudoocclusion from true occlusion or high-grade stenosis of the extracranial ICA in acute ischemic stroke: a retrospective MR CLEAN substudy. AJNR Am J Neuroradiol 2018;39:892-98 CrossRef Medline

19. Volders D, Shewchuk JR, Marangoni M, et al. Beyond the collaterals: additional value of multiphase CTA in acute ischemic stroke evaluation. Neuroradiol J 2019;32:309-14 CrossRef Medline

20. Sivan-Hoffmann R, Gory B, Armoiry X, et al. Stent-retriever thrombectomy for acute anterior ischemic stroke with tandem occlusion: a systematic review and meta-analysis. Eur Radiol 2017;27:247-54 CrossRef Medline

21. Wallocha M, Chapot R, Nordmeyer H, et al. Treatment methods and early neurologic improvement after endovascular treatment of tandem occlusions in acute ischemic stroke. Front Neurol 2019;10:127 CrossRef Medline

22. Heck DV, Brown MD. Carotid stenting and intracranial thrombectomy for treatment of acute stroke due to tandem occlusions with aggressive antiplatelet therapy may be associated with a high incidence of intracranial hemorrhage. J Neurointerv Surg 2015;7:170-75 CrossRef Medline

23. Zhu F, Labreuche J, Haussen DC, et al; TITAN (Thrombectomy in Tandem Lesions) Investigators. Hemorrhagic transformation after thrombectomy for tandem occlusions. Stroke 2019;50:516-19 CrossRef Medline

24. Pop R, Zinchenko I, Quenardelle V, et al. Predictors and clinical impact of delayed stent thrombosis after thrombectomy for acute stroke with tandem lesions. AJNR Am J Neuroradiol 2019;40:533-39 CrossRef Medline

25. Sadeh-Gonik U, Tau N, Friehmann T, et al. Thrombectomy outcomes for acute stroke patients with anterior circulation tandem lesions: a clinical registry and an update of systematic review with meta-analysis. Eur J Neurol 2018;25:693-700 CrossRef Medline

26. Wilson MP, Murad MH, Krings T, et al. Management of tandem occlusions in acute ischemic stroke: intracranial versus extracranial first and extracranial stenting versus angioplasty alone-a systematic 
review and meta-analysis. J Neurointerv Surg 2018;10:721-28 CrossRef Medline

27. Haussen DC, Turjman F, Piotin M, et al; on behalf of the TITAN (Thrombectomy In TANdem Lesions) Investigators. Head or neck first? Speed and rates of reperfusion in thrombectomy for tandem large vessel occlusion strokes. Intervent Neurol 2019;8:92-100 CrossRef

28. Lockau H, Liebig T, Henning $\mathrm{T}$, et al. Mechanical thrombectomy in tandem occlusion: procedural considerations and clinical results. Neuroradiology 2015;57:589-98 CrossRef Medline

29. Maus V, Behme D, Maurer C, et al. The ReWiSed CARe technique: simultaneous treatment of atherosclerotic tandem occlusions in acute ischemic stroke. Clin Neuroradiol 2019 May 22. [Epub ahead of print] CrossRef Medline

30. Paul AR, Entezami P, Nourollahzadeh E, et al. Simultaneous revascularization of the occluded internal carotid artery using the Solitaire as a workhorse wire during acute ischemic stroke intervention. Interv Neuroradiol 2020;26:205-10 CrossRef Medline

31. Yilmaz U, Korner H, Muhl-Benninghaus R, et al. Acute occlusions of dual-layer carotid stents after endovascular emergency treatment of tandem lesions. Stroke 2017;48:2171-75 CrossRef Medline

32. Bartolini B, Puccinelli F, Mosimann PJ, et al. Evaluating the effectiveness and safety of the carotid Casper-RX stent for tandem lesions in acute ischemic stroke. J Neurointerv Surg 2019;11:772-74 CrossRef Medline

33. Pfaff JA, Maurer C, Broussalis E, et al. Acute thromboses and occlusions of dual layer carotid stents in endovascular treatment of tandem occlusions. J Neurointerv Surg 2020;12:33-37 CrossRef Medline

34. Zinkstok SM, Roos YB; ARTIS investigators. Early administration of aspirin in patients treated with alteplase for acute ischaemic stroke: a randomised controlled trial. Lancet 2012;380:731-37 CrossRef Medline

35. Stampfl S, Ringleb PA, Mohlenbruch M, et al. Emergency cervical internal carotid artery stenting in combination with intracranial thrombectomy in acute stroke. AJNR Am J Neuroradiol 2014;35:74146 CrossRef Medline

36. Anadani M, Spiotta AM, Alawieh A, et al; on behalf of the TITAN (Thrombectomy In TANdem Lesions) Investigators. Emergent carotid stenting plus thrombectomy after thrombolysis in tandem strokes. Stroke 2019;50:2250-52 CrossRef Medline

37. Gory B, Haussen DC, Piotin M, et al; the Thrombectomy In TANdem lesions (TITAN) investigators. Impact of intravenous thrombolysis and emergent carotid stenting on reperfusion and clinical outcomes in patients with acute stroke with tandem lesion treated with thrombectomy: a collaborative pooled analysis. Eur J Neurol 2018;25:1115-20 CrossRef Medline

38. Eker OF, Buhlmann M, Dargazanli C, et al. Endovascular treatment of atherosclerotic tandem occlusions in anterior circulation stroke: technical aspects and complications compared to isolated intracranial occlusions. Front Neurol 2018;9:1046 CrossRef Medline

39. Brott TG, Hobson RW 2nd, Howard G, et al; CREST Investigators. Stenting versus endarterectomy for treatment of carotid-artery stenosis. N Engl J Med 2010;363:11-23 CrossRef Medline

40. Olafson EM, DeGrote JR, Drofa A, et al. A case series of 18 patients receiving ticagrelor after carotid stenting. J Pharm Pract 2018;31:51921 CrossRef Medline

41. Aguilar-Salinas P, Agnoletto GJ, Brasiliense LBC, et al. Safety and efficacy of cangrelor in acute stenting for the treatment of cerebrovascular pathology: preliminary experience in a single-center pilot study. J NeuroIntervent Surg 2019;11:347-51 CrossRef Medline

42. Nahab F, Kass-Hout T, Shaltoni HM. Periprocedural antithrombotic strategies in acute ischemic stroke interventional therapy. Neurology 2012;79:(Suppl 1)S174-81 CrossRef Medline

43. Neuberger U, Moteva K, Vollherbst DF, et al. Tandem occlusions in acute ischemic stroke - impact of antithrombotic medication and complementary heparin on clinical outcome and stent patency. $J$ Neurointerv Surg 2020 Jan 14. [Epub ahead of print] CrossRef Medline

44. Zhu F, Piotin M, Steglich-Arnholm H, et al; TITAN (Thrombectomy In TANdem Lesions) Investigators. Periprocedural heparin during endovascular treatment of tandem lesions in patients with acute ischemic stroke: a propensity score analysis from TITAN registry. Cardiovasc Intervent Radiol 2019;42:1160-67 CrossRef Medline

45. Ederle J, Featherstone RL, Brown MM. Percutaneous transluminal angioplasty and stenting for carotid artery stenosis. Cochrane Database Syst Rev 2007;CD000515 CrossRef Medline

46. Assis Z, Menon BK, Goyal M, et al; ESCAPE Trialists. Acute ischemic stroke with tandem lesions: technical endovascular management and clinical outcomes from the ESCAPE trial. J Neurointerv Surg 2018;10:429-33 CrossRef Medline

47. Rothwell PM, Eliasziw M, Gutnikov SA, et al; Carotid Endarterectomy Trialists' Collaboration. Analysis of pooled data from the randomised controlled trials of endarterectomy for symptomatic carotid stenosis. Lancet 2003;361:107-16 CrossRef

48. Labeyrie MA, Ducroux C, Civelli V, et al. Endovascular management of extracranial occlusions at the hyperacute phase of stroke with tandem occlusions. J Neuroradiol 2018;45:196-201 CrossRef Medline

49. EC/IC Bypass Study Group. Failure of extracranial-intracranial arterial bypass to reduce the risk of ischemic stroke: results of an international randomized trial. N Engl J Med 1985;313:1191-1200 CrossRef Medline

50. Powers WJ, Clarke WR, Grubb RL Jr, et al; COSS Investigators. Extracranial-intracranial bypass surgery for stroke prevention in hemodynamic cerebral ischemia: the Carotid Occlusion Surgery Study randomized trial. JAMA 2011;306:1983-92 CrossRef Medline

51. Saver JL, Goyal M, Bonafe A, et al; SWIFT PRIME Investigators. Stentretriever thrombectomy after intravenous t-PA vs. t-PA alone in stroke. N Engl J Med 2015;372:2285-95 CrossRef Medline

52. Campbell BC, Mitchell PJ, Kleinig TJ, et al; EXTEND-IA Investigators. Endovascular therapy for ischemic stroke with perfusion-imaging selection. N Engl J Med 2015;372:1009-18 CrossRef Medline

53. Bracard S, Ducrocq X, Mas JL, et al; THRACE investigators. Mechanical thrombectomy after intravenous alteplase versus alteplase alone after stroke (THRACE): a randomised controlled trial. Lancet Neurol 2016;15:1138-47 CrossRef Medline

54. Goyal M, Menon BK, van Zwam WH, et al; HERMES collaborators. Endovascular thrombectomy after large-vessel ischaemic stroke: a meta-analysis of individual patient data from five randomised trials. Lancet 2016;387:1723-31 CrossRef Medline

55. Nogueira RG, Jadhav AP, Haussen DC, et al; DAWN Trial Investigators. Thrombectomy 6 to 24 hours after stroke with a mismatch between deficit and infarct. N Engl J Med 2018;378:11-21 CrossRef Medline

56. Tekle WG, Hassan AE, Jadhav AP, et al; on behalf of the DAWN Trial Investigators. Impact of periprocedural and technical factors and patient characteristics on revascularization and outcome in the DAWN trial. Stroke 2020;51:247-53 CrossRef Medline

57. Albers GW, Marks MP, Kemp S, et al; DEFUSE 3 Investigators. Thrombectomy for stroke at 6 to 16 hours with selection by perfusion imaging. N Engl J Med 2018;378:708-18 CrossRef Medline

58. Marks MP, Heit JJ, Lansberg MG, et al; DEFUSE 3 Investigators. Endovascular treatment in the DEFUSE 3 study. Stroke 2018;49:200003 CrossRef Medline

59. Pires Coelho A, Lobo M, Gouveia R, et al. Overview of evidence on emergency carotid stenting in patients with acute ischemic stroke due to tandem occlusions: a systematic review and meta-analysis. $J$ Cardiovasc Surg (Torino) 2019;60:693-702 CrossRef Medline

60. Khoury NN, Darsaut TE, Ghostine J, et al; EASI Trial Collaborators. Endovascular thrombectomy and medical therapy versus medical therapy alone in acute stroke: a randomized care trial. J Neuroradiol 2017;44:198-202 CrossRef Medline

61. Poppe AY, Jacquin G, Stapf C, et al. A randomized pilot study of patients with tandem carotid lesions undergoing thrombectomy. $J$ Neuroradiol 2019 Sep 26. [Epub ahead of print] CrossRef Medline

62. Poppe AY, Stapf C, Raymond J. Letter by Poppe et al regarding article, "Emergent Carotid Stenting After Thrombectomy in Patients With Tandem Lesions.” Stroke 2017;48:E182 CrossRef Medline 


\section{AUTHOR QUERIES}

\section{AUTHOR PLEASE ANSWER ALL QUERIES}

AQfund-The table below includes funding information that you provided in Manuscript Central when you submitted the manuscript. This funding information will not appear in the article, but it will be provided to Crossref and made publicly available. Please check it carefully for accuracy and mark any necessary corrections. If you would like statements acknowledging financial support to be published in the article itself, please make sure that they appear in the form of a footnote on page 1. Statements in the footnote will have no bearing on funding data deposited with Crossref and vice versa.

AQ:au-Please check authors' names, authors' affiliations, and footnote information. Please verify that all are correct.

AQ:abbr-Please verify the abbreviations.

AQ:corrs-Would you like to add a Twitter handle to your proof? If so, please provide a Twitter handle.

AQ:fig_-Please carefully review your figures for quality and accuracy. Do not adjust your monitor in an attempt to improve their quality as this will not match the printed version. If you deem any of the images to be unacceptable, please provide replacement figures with your proof corrections. And also Please review your figure legends carefully. Verify that all information is as intended after typesetting.

AQ:tab-Please review your tables carefully. Verify that all information is as intended after typesetting.

AQ:disc—Please verify the disclosures.

A-Author: Was the money for Dr Poppe and Bristol-Myers Squibb-Pfizer, Bayer, and Servier paid to an individual or institution? Please provide the complete name of Bayer.

B-Author: If "significant" is not used in a statistical sense, please choose another word.

C-Author: Please verify the URL.

D-Author: Is "obviate" the word intended here? It means "anticipate and prevent" or "remove."

E-Author: Please review the edit of the sentence beginning with "Some."

F-Author: Please expand HERMES.

G-Author: Please verify the collaborators. 